\title{
Healthcare Industry Improvement with Business Intelligence
}

\author{
Mihaela IVAN, Manole VELICANU \\ Bucharest University of Economic Studies, Bucharest, Romania \\ ivanmihaela88@gmail.com, manole.velicanu@ie.ase.ro
}

The current paper highlights the advantages of big data analytics and business intelligence in the healthcare industry. In the paper are reviewed the Real-Time Healthcare Analytics Solutions for Preventative Medicine provided by SAP and the different ideas realized by possible customers for new applications in Healthcare industry in order to demonstrate that the healthcare system can and should benefit from the new opportunities provided by ITC in general and big data analytics in particular.

Keywords: Business Intelligence, Healthcare Analytics, Use-Cases, Real-Time Processing

1 Introduction

The concepts used and presented in this paper are Big Data, which is a challenge nowadays, In-Memory, which is a new Business Intelligence technology and Analytics, which is a use case [1] [2]. Nowadays, it is very important to present the role of Business Intelligence technology in the healthcare sector.

Global data production is expected to increase at an astonishing 4,300 per cent by 2020 from 2.52 zettabytes in 2010 to 73.5 zettabytes in 2020 [3]. Big data refers to the vast amount of data that is now being generated and captured in a variety of formats and from a number of disparate sources. Big data analytics is the intersection of two technical entities that have come together. First, there's big data for massive amounts of detailed information. Second, there's advanced analytics, which can include predictive analytics, data mining, statistics, artificial intelligence, natural language processing, and so on. Put them together and you get big data analytics.

In [4], Prof. dr. med. Karl Max Einhäupl considered that "in a hospital like Charite it's an unending stream of data every day. We see an unending stream of data every day and it is unconditional important that we collect this data, filter, control it and reuse it for patient care, or for teaching, or for driving research. In the medical field, it is critical that we move away from the flood of paper that is overwhelming doctors today; that we continually move toward electronic data capture." This means that if you have the right information at the right time then everything it's possible.

The current paper is an extended version of the work presented at the 14th International Conference on Informatics in Economy, IE 2015, 30 April - 03 May 2015, Bucharest, Romania [5].

\section{Healthcare Analytics}

When discussing about healthcare analytics, it is important to ask how are the statistics numbers regarding the usage of analytics in healthcare and how this affects the end user's knowledge? In the Figure 1 below these numbers are represented, $10 \%$ are those who use analytics today and approximately $75 \%$ need analytics [6]. The disadvantage of those who are not using analytics feature is that they can't make use of all data because the ability to manage all data is getting difficult. On the other side, those who use analytics today are missing new insights, which mean they are not able to imagine the potential. 


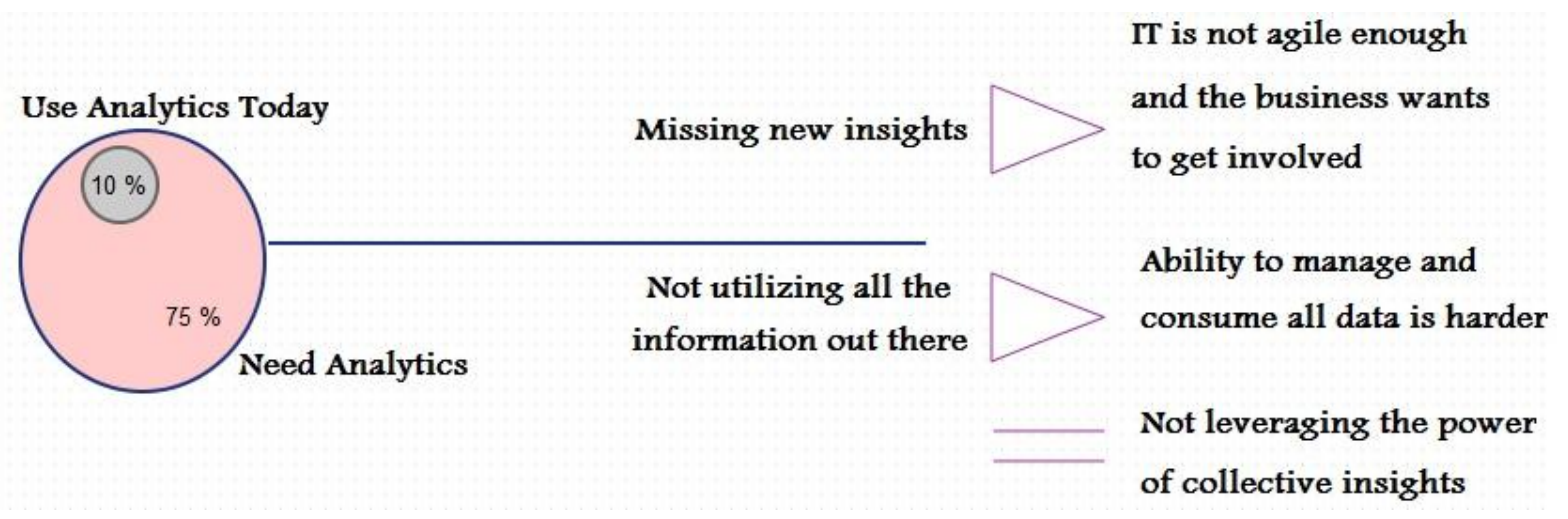

Fig. 1. Healthcare Analytics

The power of collective insights is realized by following three steps:

- Engage: predict demand and supply of Supply Chain;

- Visualize: understand the customer's thoughts;

- Predict: provide the proper offers and services to every customer; also predict new market trends and innovate new products [7].

Healthcare organizational data it is used in diverse cases like surgical analytics, share healthcare visualizations and have the clinicians share the processes. Profitability and quality analysis for management can provide the critical insights to obtain the organizations goals and gain competitive advantages. Analytical applications are developed to provide the base for the use of analytics in an enterprise [8].

We must consider that analytics is about people and their needs. We can see in the Figure 2 why is this evolution so important and how the people's thinking are.
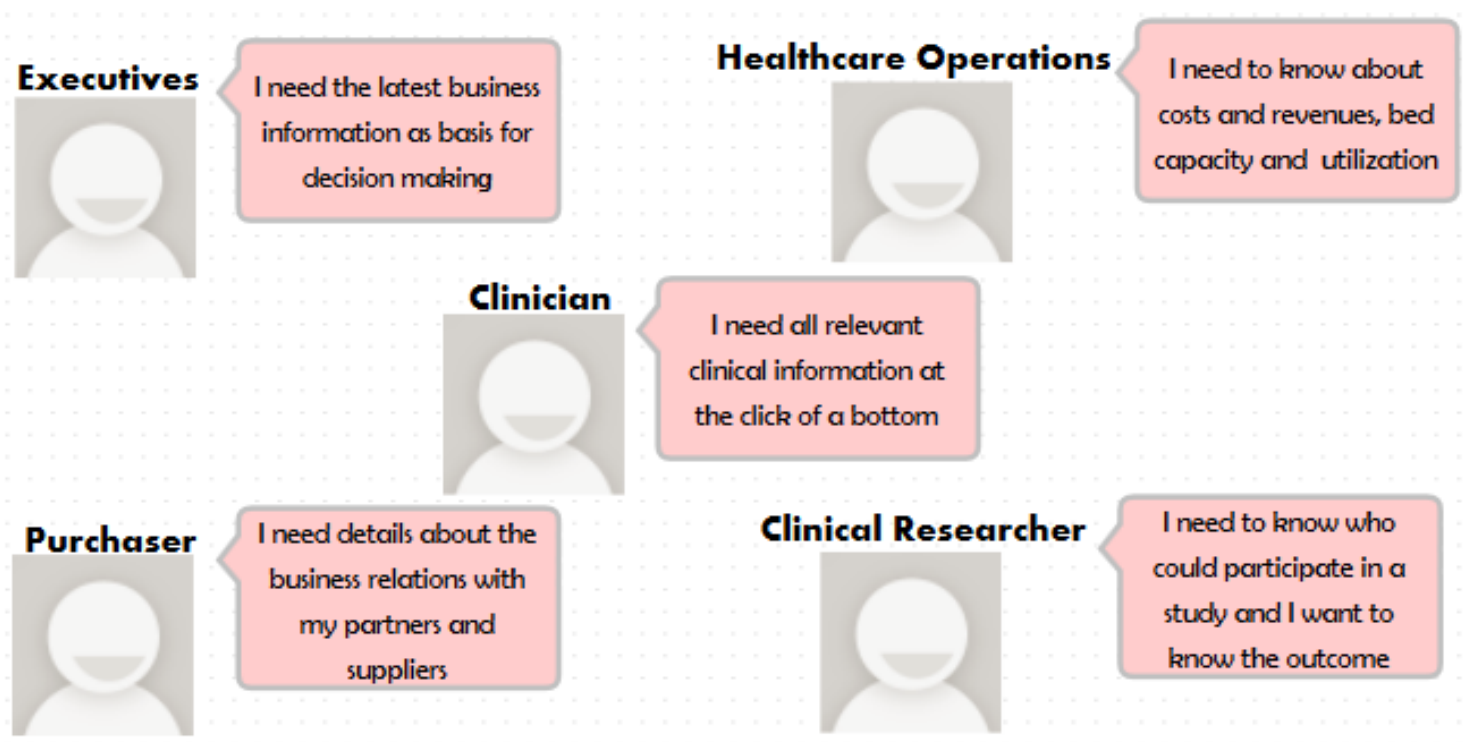

Fig. 2. Analytics is for People

The focus is on the empathy of the end user like executives, healthcare operations, clinician, purchaser and clinical researcher. This is in fact the user experience with these useful tools. The user experience can be sufficient in terms of satisfaction if the tools have beautiful UI (user interface) and an easy adoption [9].

As presented in Figure 3, in the healthcare industry it is very important to help the organizations to measure and improve treatment quality, to address growing 
concerns, to better manage revenue and to increase the overall satisfaction.

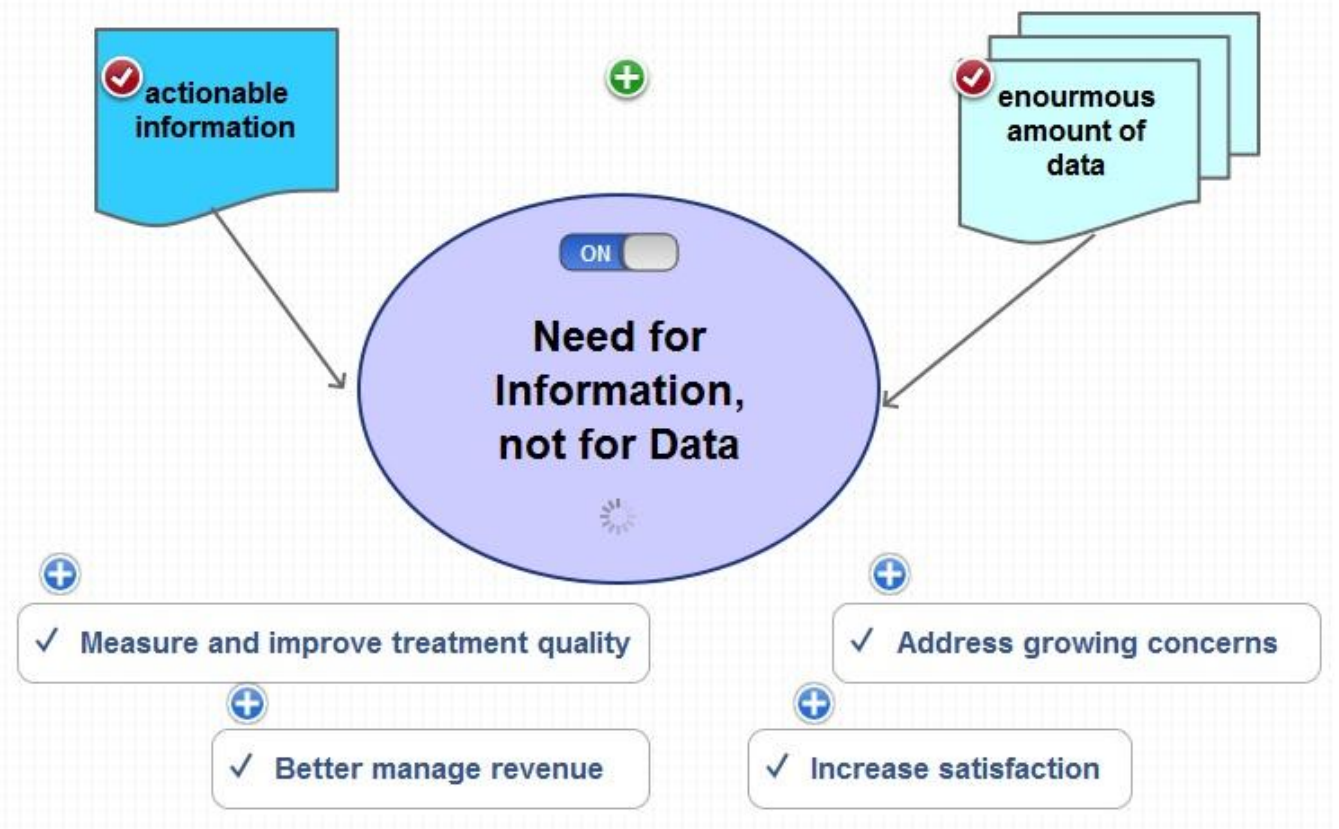

Fig. 3. Information vs. data in healthcare industry

There is not necessary to collect more data, because the companies' needs are to reach more information, considering that in these days many companies are already confronted with processing enormous amount of data. In our opinion, the actual context of healthcare analytics it's about redefining the possible, while the future evolution can be described in terms like efficiency, performance, data quality, real-time analytics for patients, doctors and medical researchers.

\section{Healthcare Analytics Solutions}

A Real-Time Healthcare Analytics Solution for Preventive Medicine is a solution developed by SAP. It let users to see their analytics and to use all the functionalities of SAP HANA which is behind this application. This solution saves time and can be easily customized for any use case [10] [11] [12].

Below are collected different healthcare usecases realized by different customers for new applications in healthcare industry.

\section{Acceleration of most used SAP Patient Management transactions}

Like the clinical workstation, the reasons are the following:

- a lot of user complaints related to performance;
- the transaction is a key one as it offers a view on all patients of a given ward with important data.

Many users work with it and use the refresh function which creates additional system load. This use case is currently being implemented. We could think of further opening it up to multiple providers in order to provide access to patient information of the complete Health Information Network (would need to be based on IHE specifications).

\section{Clinical Research Support for cancer patients}

This healthcare use-case has the following advantages:

- help medical researchers and physicians comprising up-to-date clinical and medical information into research processes;

- ability to access all relevant data across organizational boundaries real-time;

- analyses of clinical data based on structured as well as unstructured information;

- create patient cohorts for clinical trials;

- quickly determine Patient/Trial matching; 
- could of course be applied to other patients and specialties;

- use cases is reflected in SAP Solution in Early Adoption "Medical Research Insights";

- this use case could be useful for these customers NCT, DKFZ hospitals.

\section{Patient Segmentation}

This use-case help Healthcare Payers to quickly analyze their patient population in order to determine potential candidates for a disease management program (e.g. diabetes prevention). Potential customers for this use-case could be Healthcare Payers and Health Insurances.

\section{Health Plan Analytics}

This use-case will support Healthcare Payers to analyze the effectiveness of their health programs (e.g. ROI and Performance Analysis of Disease Management Programs covering morbidity clustering). As in the previous use-case, potential customers could be also Healthcare Payers and Health Insurances.

\section{Multi-Resource Planning}

In this situation, the use-case can help Healthcare Providers to quickly recalculate their outpatient schedules or inpatient surgery plans based on different types of incidents like unavailability of doctors etc. Potential customers are Healthcare Providers.

\section{Treatment outcome analysis}

This will help Healthcare Providers to analyze their patient treatment outcome and costs by considering diagnosis and DRG codes, length of stay, services performed, claims and revenues. This could also be used to support the contract negotiation process with the payers, by providing hospitals with the information support on the real costs for a specific patient group. Potentially extend this to a multi provider or ACO (Accountable Care Organization) scenario for the US. As in previous situations, potential customers are Healthcare Providers.

\section{Evidence-based medicine}

Evidence-based medicine (EBM) aims to apply the best available evidence gained from the scientific method to clinical decision making. The use case is to suggest medical guidelines based on past patient treatments. Potential customers are Healthcare Providers.

\section{Drug Recall}

This use-case provide fast and efficient recall procedures by determining quickly all the patients having been administered the drug to be recalled including their location and contact information. Potential customers are Healthcare Providers.

\section{Track \& Trace of Medical Products}

This use-case offer monitoring of the logistic chain of medical and pharmaceutical products from the raw material to the point of consumption by the patient including efficient counterfeit prevention. Potential customers are Healthcare Providers.

\section{Prevention of Fraud and Abuse}

This support analysis of incoming claims in comparison to the claims history with the aim of detecting cases of fraud and abuse. Originally HANA Olympics use case submitted by Jim Brett (Partner Manager for E\&Y) Jim \& Steve pushing on partner development in the US GRC cross industry use case "Instant Compliance" under evaluation, Healthcare has been asked to address requirements. Potential customers are Healthcare Payers.

\section{Real-time patient monitoring}

This use-case help Monitoring patients in real-time and triggering alerts of necessary interventions based upon incoming data (e.g. blood pressure). This use case is an example for a set of use cases like

- $\quad$ MEWS (modified early warning score) in the ICU area; 
- Elderly patients at home.

Potential customers are Healthcare

Providers.

\section{Determination of copayment rates}

Offer an insured patient the possibility to quickly find out which copayment he would have to make for a given treatment. This service could be offered by a health insurance through a portal or mobile device to their customers. It would create the required output based on the insured person's health plan and on the already consumed services. This determination is data intensive and could be accelerated through HANA. Potential customers are
Health Insurances for their insured persons or Patients directly.

\section{Prevention of Claims Rejection}

This help medical controllers or physicians by informing them that a case might be subject to a payer investigation (e.g. MDK in Germany) because of a mismatch between claims and medical facts and other characteristics like length of stay, age etc. Potential customers are Healthcare Providers.

In the below Table 1 is realized a comparative analysis of use-cases which will be implemented in the healthcare industry and their key benefits are highlighted.

Table 1. Comparative analysis of Healthcare use-cases

\begin{tabular}{|l|l|l|}
\hline Use cases & Potential customers & Key benefits \\
\hline $\begin{array}{l}\text { Acceleration of most used SAP Patient } \\
\text { Management transactions }\end{array}$ & Healthcare industry of \\
\hline $\begin{array}{l}\text { Clinical Research Support for cancer } \\
\text { patients }\end{array}$ & $\begin{array}{l}\text { NCT and DKFZ hospitals } \\
\text { from Munich }\end{array}$ & $\begin{array}{l}\text { Increased pration processing } \\
\text { satisfaction }\end{array}$ \\
\hline Patient Segmentation & $\begin{array}{l}\text { Healthcare Payers and } \\
\text { Health Insurances }\end{array}$ & Cost savings for hospitals \\
\hline Health Plan Analytics & $\begin{array}{l}\text { Healthcare Payers and } \\
\text { Health Insurances }\end{array}$ & Real-time analysis \\
\hline Multi-Resource Planning & Healthcare Providers & Time saving for planning \\
\hline Treatment outcome analysis & Healthcare Providers & $\begin{array}{l}\text { Better } \\
\text { management }\end{array}$ \\
\hline Evidence-based medicine & Healthcare Providers & $\begin{array}{l}\text { Better clinical decision } \\
\text { making process }\end{array}$ \\
\hline Drug Recall & Healthcare Providers & $\begin{array}{l}\text { Efficient } \\
\text { procedures }\end{array}$ \\
\hline Track \& Trace of Medical Products & Healthcare Providers & $\begin{array}{l}\text { Efficient counterfeit } \\
\text { prevention }\end{array}$ \\
\hline Prevention of Fraud and Abuse & Healthcare Payers & Better fraud prevention \\
\hline Real-time patient monitoring & Healthcare Providers & \begin{tabular}{l} 
Real-time monitoring \\
\hline Determination of copayment rates \\
insured persons or Patients \\
directly budget planning
\end{tabular} \\
\hline Prevention of Claims Rejection & Healthcare Providers & $\begin{array}{l}\text { Efficient } \\
\text { management }\end{array}$ \\
\hline
\end{tabular}

Our solution proposed in the healthcare industry is based on the use-cases presented above and has the following objectives:

- real-time analysis of hospital patient management data;

- significant speed up of reporting processes;
- monitoring clinical quality of care and patient safety.

We have to eliminate the barriers of space and time between the patient, the administrator and the doctor. It's about having the data at the right moment when healthcare is delivered and consumed. The 
approach is to have a real-time platform which delivers medical insights while reducing costs [13].

\section{How Big Data Impacts Healthcare}

The speed of the challenges in the healthcare industry continue to grow. But the evolution in computing technology needs effective personalized medicine and specific treatments according to patients' individual characteristics [14].

\section{Many benefits of Big Data}

Business executives from the healthcare agencies highlighted the benefits of big data. The question is "what is driving the push for big data?" The response is quite simple: the demand to create more value in healthcare. The benefits of big data are presented in Figure 4.

$63 \%$

Will help track and manage population health more efficiently

$62 \%$

Will significantly improve patient care within the military health and VA systems

$60 \%$

Will enhance the ability to deliver preventive care

Fig. 4. Many benefits of Big Data

To make use of this IT evolution means to use proper data at the right moment. In fact is a work with almost the most complex and disconnected data sets of any industry. This problem has been a long-term challenge for healthcare providers. The healthcare organizations have adopted IT platforms that simplify processes and IT systems. Also, their scope is to expand and improve the spread of care at a lower cost. The evolving IT platforms present the information with visualization tools that put actionable insights into the hands of caregivers and patients, enabling providers to invent new healthcare practices as needed. The benefits of this approach are: better preventive care; IT simplification; and improved, more personalized treatment [15].

\section{Patients Taking Charge of Health \\ Choices}

The new IT platforms will need to serve the health economy. In this way the focus should be on patient outcomes. A research show the percentages of patients that would do something else in order to have a lower cost. In the Figure 5 below are represented these percentages. 


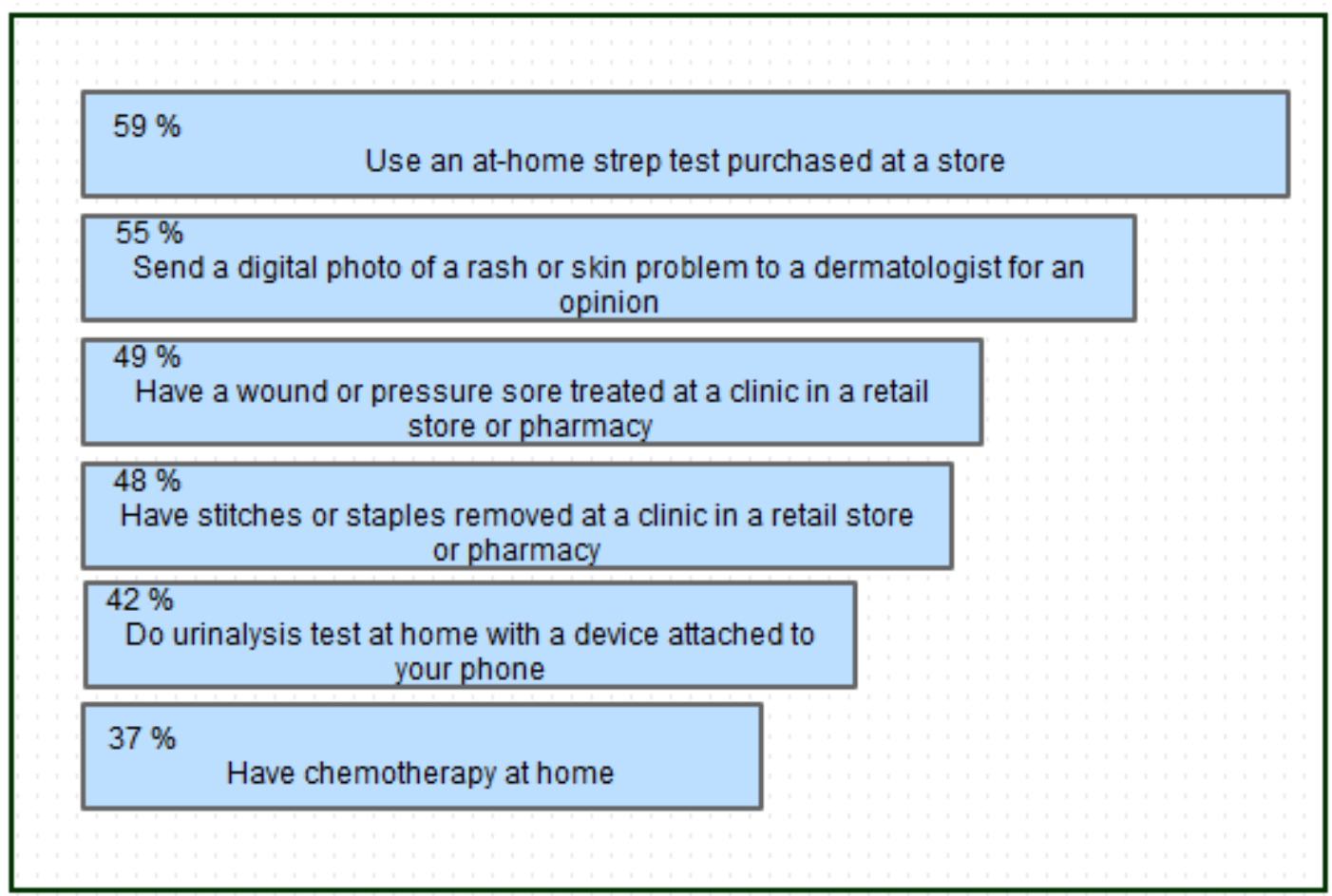

Fig. 5. Patients Taking Charge of Health Choices [16]

The patients know less things about their healthcare than they know about their food at a breakfast. The scope of IT platforms is simplification and this simplification is for patients to make informed decisions. According to a Health Research Institute survey (Figure 5) more accurate and fast available information may cut the cost of healthcare while improving its quality. Many patients are actively looking to reduce costs and improve their quality. The survey found, for example, shows that patients would likely choose nontraditional forms of healthcare, such as at-home healthcare analysis tests using a specific mobile application or a device attached to a smartphone, if these cost less [16].

\section{Conclusions}

In conclusion is time for change in Healthcare sector. The use of analytics will enable putting the right data at the fingertips of the people with the potential to generate lifesaving or lifestyle improving insights. Big data offers breakthrough possibilities for new research and discoveries, better patient care, and greater efficiency in health and health care, as detailed in the July issue of Health
Affairs [17]. The future of Healthcare industry is under construction, but it's so clear the design of the healthcare IT platform of tomorrow means imagining not only how data is used but also how healthcare is delivered. We believe that big data analytics can significantly help healthcare research and ultimately improve the quality of life for patients from any domain.

\section{Acknowledgment}

This paper was co-financed from the European Social Fund, through the Sectorial Operational Program Human Resources Development 2007-2013, project number POSDRU/159/1.5/S/138907 "Excellence in scientific interdisciplinary research, doctoral and postdoctoral, in the economic, social and medical fields -EXCELIS", coordinator The Bucharest University of Economic Studies.

\section{References}

[1] M. L. Ivan, "Characteristics of InMemory Business Intelligence," Informatica Economică, vol. 18, no. 3, 2014, pp. 17-25.

[2] A. Bara, I. Botha, V. Diaconiţa, I. Lungu, A. Velicanu, M. Velicanu, "A model for 
Business Intelligence Systems' Development," Informatica Economică, vol. 13, no. 4, 2009, pp. 99-108.

[3] Big Data Strategy - Improved understanding through enhanced dataanalytics capability, June 2013, Available at http://www.finance.gov.au/agict

[4] J. Flintrop, E. A. Richter-Kuhlmann, H. Stüwe, Interview mit Prof. Dr. med. Karl Max Einhäupl, Vorstandsvorsitzender der Charité, Available at: http://www.aerzteblatt.de/archiv/62999/Int erview-mit-Prof-Dr-med-Karl-Max-

Einhaeupl-Vorstandsvorsitzender-der-

Charite-Universitaetsmedizin-Berlin-Wirkoennen-uns-keine-Klinik-leisten-dienicht-zu-den-besten-gehoert

[5] M. L. Ivan, M. Velicanu, I. Taranu, "Using Business Intelligence in Healthcare System," The 14th International Conference on Informatics in Economy, IE 2015, 30 April-03 May, 2015, Bucharest, Romania, ISSN 22847472.

[6] C. Gadalla, A Technical Guide to Leveraging Advanced Analytics Capabilities from SAP, Available at: http://www.slideshare.net/SAPanalytics/bi 2015-charlesgadallatechguideleveraginganalytics

[7] SAP HANA Platform, Rethinking Information Processing for Genomic and Medical Data, Available at: https://www.sap.com/bin/sapcom/en_us/d ownloadasset.2013-02-feb-11-20.saphana-platform-rethinking-informationprocessing-for-genomic-and-medicaldata-pdf.html

[8] Business Intelligence and Analytics for Healthcare, Available at: http://www.perficient.com/Industries/Heal thcare/Business-Intelligence-Analytics

[9] K. Gaddy, "Making the most of analytics," Insights, Available at: http://www.utilityanalytics.com/resources/ insights/making-most-analytics
[10] Real-Time Healthcare Analytics Solution for Preventative Medicine, United Software Associates Inc., Available at: http://marketplace.saphana.com/p/3323

[11] T. Knabke, S. Olbrich, S. Fahim, "Impacts of In-memory Technology on Data Warehouse Architectures - A Prototype Implementation in the Field of Aircraft Maintenance and Service", in Advancing the Impact of Design Science: Moving from Theory to Practice, Lecture Notes in Computer Science, Springer, Vol. 8463, 2014, pp. 383-387

[12] Big Data Analytics, September 14, 2011 , Available at: http://tdwi.org/research/2011/09/bestpractices-report-q4-big-dataanalytics.aspx

[13] Healthcare Solutions, Available at: saphana.com/community/learn/solutions/h ealthcare

[14] R. M. Müller, H. J. Lenz, Business Intelligence, Springer-Verlag, Berlin Heidelberg, 2013, ISBN 978-3-64235559-2, pg. 323.

[15] PwC, Health Research Institute, "Healthcare's new entrants: who will be the industry's amazon.com?," April 2014, Available at: http://www.pwc.com/us/en/healthindustries/healthcare-new-

entrants/assets/pwc-hri-new-entrant-chartpack-v3.pdf

[16] "How Big Data Impacts Healthcare", Harvard Business Review, 2014, Available at: https://hbr.org/resources/pdfs/comm/sap/1 8826_HBR_SAP_Healthcare_Aug_2014. pdf

[17] "Using Big Data to Transform Care," Health Affairs, July 2014, Vol. 33, Issue 7, Available at: content.healthaffairs.org/content/33/7.toc 

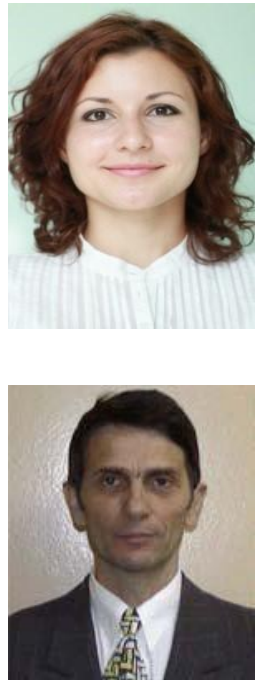

Programming languages

Mihaela Laura IVAN graduated from the Faculty of Cybernetics, Statistics and Economic Informatics of the Bucharest University of Economic Studies in 2011. She also finished the Master's degree in Economic Informatics in 2013, at the Bucharest University of Economic Studies. Starting with 2013, Mihaela is a PhD candidate at Bucharest University of Economic Studies in the field of Economic Informatics. At the present, she is a SAP Development Consultant at SAP Near Shore Centre Romania.

Manole VELICANU is a Professor at the Economic Informatics Department at the Faculty of Cybernetics, Statistics and Economic Informatics from the Academy of Economic Studies of Bucharest. He has graduated the Faculty of Economic Cybernetics in 1976, holds a $\mathrm{PhD}$ diploma in Economics from 1994 and starting with 2002 he is a PhD coordinator in the field of Economic Informatics. His fields of interest include: Databases, Design of Economic Information Systems, Database Management Systems, Artificial Intelligence, 